\title{
A CONTRIBUIÇÃO DO PRINCIPIO DA FELICIDADE PARA A CONSTRUÇÃO DE CIDADES INTELIGENTES
}

\author{
Valmir César Pozzetti* \\ Marie Joan Nascimento Ferreira ${ }^{\dagger \square \square}$
}

\section{RESUMO}

O objetivo desta pesquisa foi o de analisar os reflexos do princípio da felicidade no meio ambiente urbano, na construção da felicidade individual ou coletiva. A metodologia utilizada foi a do método dedutivo; quanto aos meios a pesquisa foi a bibliográfica e quanto aos fins, qualitativa. A conclusão a que se chegou foi a de que o princípio da felicidade se adequa positivamente no meio ambiente urbano, em especial nas já existentes cidades inteligentes. $\mathrm{O}$ resultado obtido foi o de que o Princípio da Felicidade traz um grande contributo para o desenvolvimento sustentável,com foco no ambiental, social e urbanístico.

PALAVRAS-CHAVE: bem-estar, cidade inteligente, dignidade, meio ambiente urbano, princípio da felicidade.

\section{THE CONTRIBUTION OF THE HAPPINESS PRINCIPLE TO THE BUILDING OF SMART CITIES}

\begin{abstract}
The objective of this research was to analyze the reflexes of the happiness principle in the urban environment, in the construction of individual or collective happiness. The methodology used was that of the deductive method; in terms of means, the research was bibliographic and in terms of ends, qualitative. The conclusion reached was that the happiness principle fits positively in the urban environment, especially in the already existing smart cities. The result obtained was that the Principle of Happiness makes a great contribution to sustainable development, with a focus on the environmental, social and urban development.
\end{abstract}

KEYWORDS: well-being, smart city, dignity, urban environment, principle of happiness.

\section{INTRODUÇÃO}

O Meio ambiente urbano é um meio artificial modificado pelo ser humano pra atender às suas necessidades, de acordo com a cultura e forma de vida dos seres que a

\footnotetext{
* Pós-Doutor em Direito à Alimentação Sadia pela Universitàdegli Studi di Salerno/Itália. Pós Doutor em Direito Ambiental pela Escola de Direito Dom Helder Câmara/MG. Doutor em Biodireito/Direito Ambiental pela Université de Limoges/França. Mestre em Direito do Urbanismo e Meio Ambiente, pela Université de Limoges/França. Professor Adjunto da Universidade Federal do Amazonas - UFAM e Professor Adjunto da Universidade do Estado do Amazonas - UEA. Email: v_pozzetti@ hotmail.com

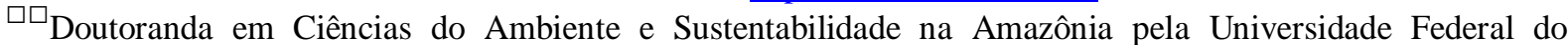
Amazonas - UFAM. Mestre em Direito Ambiental pela Universidade do Estado do Amazonas - UEA. Email: marie-joan@hotmail.com
} 
habitam. Dessa forma, o homem foi construindo as cidades e sem perceberem, elevaram o nível de insatisfação com aquilo que acabou produzindo: construções fora do planejamento, um grande quantidade de veículos que atendem aos interesses das montadoras de veículos, sem levar em conta a qualidade do ar; o descarte inadequado de dejetos sólidos e líquidos de forma indiscriminada no meio ambiente; a incansável busca por salários maiores, sem se preocupar com a qualidade de vida que passou a ter nesse ambiente, com alimentação industrializada e diversos outros fatores que fizeram com que determinadas cidades abassem por se tornarem tóxicas, com uma qualidade de vida inadequada.

Dessa forma, o homem contemporâneo busca mudar a estrutura dessas cidades que construiu e realiza uma busca consciente e inconsciente, para obter a felicidade; ou seja, viver em um meio ambiente urbano que propicie qualidade de vida e, vida usufruída com felicidade.

No entanto a felicidade é um sentimento e, por essa razão, é subjetiva, uma vez que cada pessoa sente e pensa de forma diversa. Nesse sentido, em um contexto geral, a felicidade seria o bem-estar que leva o indivíduo ao êxtase de toda sua plenitude como ser humano; para isso deve ter corpo e mente equilibrados e o meio ambiente urbano em que ele vive, deve ser adequado às suas necessidades e ao conceito de dignidade, para que ocorra esse equilíbrio.

Para tanto, a felicidade não busca apenas a literalidade do ato de ser feliz, mas também o alcance da dignidade da pessoa humana, com garantias de políticas públicas para a efetivação dos direitos fundamentais, com qualidade de vida.

O meio ambiente urbano deve possuir equipamentos necessários para prover a qualidade de vida de cidadãs e cidadãos que habitam esse espaço, almejando o bem comum de todos e todas, estabelecendo parâmetros em diretrizes e políticas públicas para melhoria do modo de viver, com dignidade, como saúde e educação, alcançando o desenvolvimento sustentável. Nesse sentido, o princípio da felicidade; por sua vez, contempla justamente esse bem-estar tão questionado, mas não aplicado por falta de políticas públicas com ênfase na revisão do meio ambiente urbano de várias localidades.

Há que se destacar que a preocupação, na viabilidade do empoderamento das cidades através da sustentabilidade, vislumbra a criação de "cidades inteligentes", com análise do meio ambiente urbano para efetivar medidas de desenvolvimento na economia, na educação, na saúde, entre outros. 
Cumpre observar, que a primeira cidade escolhida como objeto de estudo, localizada na região amazônica, no Estado do Pará, foi o município "Canaã dos Carajás”, que diante da sua condição econômica e formação conturbada, pode mudar a vida dos seus habitantes com o afinco dos pesquisadores, gestores públicos e a população.

Dessa forma, o objetivo dessa pesquisa será o de analisar a importância da aplicação do princípio da felicidade no meio ambiente urbano e demonstrar os possíveis reflexos e mudanças que este meio ambiente pode desenvolver de forma sustentável.

A problemática que envolve essa pesquisa é: qual a contribuição do Princípio da Felicidade na formação das cidades inteligentes?

A pesquisa se justifica, em virtude de que as questões ambientais que envolve a construção de cidades, sem qualquer planejamento, resultando em uma cidade "tóxico", deve ser alterada, buscando utilizar-se de mecanismos e instrumentos voltado para a construção de uma cidade ambientalmente sustentável; e ela somente o será, se os seus habitantes tiverem como perspectiva, a felicidade.

Dessa forma, a utilização do princípio da felicidade como mecanismo indutor da melhoria do meio ambiente urbano, gerará qualidade de vida, com contornos sustentáveis; principalmente no tocante à dignidade dos seres humanos e não humanos; buscando o bem comum na educação, na saúde, na economia, na justiça social, melhores condições de habitação, melhores empregos, e muito mais.

A metodologia que será utilizada nessa pesquisa, será o método dedutivo; quanto aos meios a pesquisa será bibliográfica, com uso da doutrina, legislação e jurisprudência; quanto aos fins, a pesquisa será qualitativa.

A aplicação, tanto o princípio da felicidade como o meio ambiente urbano conduzem qualquer população, para a qualidade de vida, com contornos sustentáveis, principalmente na dignidade das vidas humanas e não humanas, buscando o bem comum na educação, na saúde, na economia, na justiça social, melhores condições de habitação, melhores empregos, e muito mais.

\section{PRINCÍPIO DA FELICIDADE}

Os Princípios fizeram parte do processo de integração das normas jurídicas; entretanto, na contemporaneidade, possuem força normativa, sendo considerados "normas" 
jurídicas. Não podem ser considerados "leis", mas possuem força normativa para subsidiar a existência, o surgimento das leis; pois uma lei que surge no universo jurídico, contrariando princípios fundamentais, está fadada à revogação.

Assim sendo, o "Princípio" traz, na visão literal, o significado de começo, o início de condutas a serem seguidas; porém, no ordenamento jurídico os princípios refletem as diretrizes fundamentais que sustentam em uma nação, a elucidação das necessidades dos jurisdicionados, conforme destacam Pozzetti, Pozzetti e Pozzetti (2020, p. 177, grifo nosso):

Os Princípios são mecanismos normativos que subsidiam a construção de uma norma jurídica. Nenhuma Lei terá força jurídica, caso descumpram os Princípios Jurídicos, uma vez que quem constrói os princípios é a própria sociedade de determinada região/país em virtude da sua cultura e costumes.

No Brasil, a legislação é conduzida e orientada por princípios, explícitos e implícitos, como pilares que edificam o ordenamento, conforme destaca a Constituição da República Federativa do Brasil - $\mathrm{CF} / 88$ :

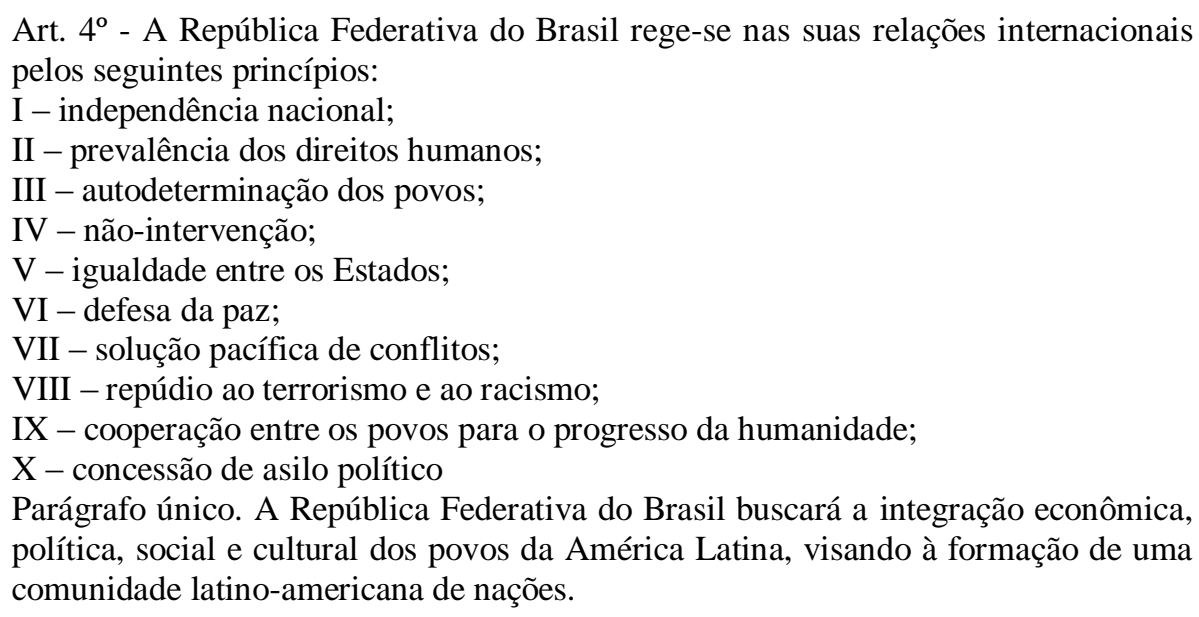

Vê-se, portanto, que a Lei mais importante do Brasil, a Constituição Federal - CF/88 - traz em seus primeiros parágrafos a importância dos princípios, nas suas relações internacionais; elevando assim, os princípios à uma categoria de "norma" não mais integrativa, mas sim, construtiva, deixando claro que qualquer relação externa do Brasil, que não seguir, que não for fundamentada nesses princípios descritos no art. $4^{\circ}$, estará indo na contramão do que determina a $\mathrm{CF} / 88$.

A legislação brasileira, infraconstitucional, também recorre aos princípios para oferecer justiça aos jurisdicionados, conforme a Lei de Introdução às normas do Direito Brasileiro - LNDB, DECRETO-LEI No 4.657/1942: 
Art. $4^{\circ}$ - Quando a lei for omissa, o juiz decidirá o caso de acordo com a analogia, os costumes e os princípios gerais do direito.

Assim, os princípios constroem os pilares da sociedade, com aplicação no mundo jurídico, para estabelecer esse elo com o seu povo e que garanta segurança jurídica para todas as pessoas.

E é nesse sentido que Ávila (2021, p. 105 e 106, grifo nosso) esclarece:

\begin{abstract}
As considerações antes feitas demonstram que os princípios não são apenas valores cuja realização fica na dependência de meras preferências pessoais. Eles são, ao mesmo tempo, mais do que isso e algo diferente disso. Os princípios instituem o dever de adotar comportamentos necessários à realização de um estado de coisas ou, inversamente instituem o dever de efetivação de um estado de coisas pela adoção de comportamentos a ele necessários. Essa perspectiva de análise evidencia que os princípios implicam comportamentos, ainda que por via indireta e regressiva. Mais ainda, essa investigação permite verificar que os princípios, embora indeterminados, não o são absolutamente. Pode até ter incerteza quanto ao conteúdo do comportamento a ser adotado, mas não há quanto à sua espécie: o que for necessário para promover o fim é devido.
\end{abstract}

Nota-se, portanto, a importância dos princípios para alcançar o fim principal na instrumentalização dos institutos jurídicos e a sua devida aplicação para basilar e elucidar as condutas jurídicas necessárias para que a justiça seja feita.

Dessa forma, os princípios são oriundos da cultura e desenvolvimento intelectual e moral de uma povo e, dessa forma, à medida em que esse povo evolui intelecto e moralmente, novos princípios vão surgindo para atender a necessidade de proteção de direitos fundamentais dessa população. Por exemplo, no pretérito, o homem em estado ainda muito rudimentar, saia de seu espaço físico para conquistar outros territórios e outros povos e, à medida em que lograva êxito nessas conquistas, o vencido se tronava escravo do vencedor e os bens do vencido passavam a ficar sob o domínio do vencedor.

Com a evolução moral da sociedade, as guerras e a escravidão, físicas foram sendo banidas do meio social; entretanto o homem manteve sua necessidade de exercer alguns controles, tais como a escravidão psicológica do outro, concessão de possibilidades de trabalhos, mas sem isonomia, mantendo postos de trabalhos sem dignidade, sem o bem-estar que permitiria a execução de um trabalho que trouxesse dignidade ao trabalhador, etc. Dessa forma, os cientistas jurídicos começaram a desenvolver pesquisas que fizeram vir a tona a necessidade de se criar novos princípios, como o desenvolvimento jurídico do princípio da fraternidade que a cada dia ganha mais força jurídica no âmbito de diversas sociedades globais, tidas como sociedades evoluídas. Nesse mesmo sentido, os pesquisadores agora se debruçam na construção do "Princípio da Felicidade", buscando demonstrar a necessidade 
que o ser humano tem de ser feliz, de exercer uma atividade profissional que lhe traga felicidade, de viver em um espaço urbano que lhe traga felicidade, etc.

Assim sendo, o ordenamento jurídico contemporâneo deve buscar trabalhar o Princípio da Felicidade, para estabelecer condutas sociais que modifiquem comportamento da sociedade e do Poder Público para assegurar que o "homem feliz" possa usufruir do Princípio da Dignidade da Pessoa humana em sua integralidade.

Dessa forma, é necessário que o cientista do direito busque mecanismos para definir o que seria "felicidade" para que ela possa ser buscada e assegurada pelo direito. Acepções para a palavra "felicidade" perpassam pela situação a ser aplicada ou até de forma pessoal, conforme a imaginação e a necessidade de cada um.

Ferreira (2016, p. 10) ao falar de felicidade destaca que "não existe significado, o homem a conceitua conforme sua imaginação, sua necessidade naquele momento, ou ao comparar o passado com o futuro, ou ainda, ao sonhar com mudanças internas e externas para o futuro", pois a felicidade muda sua concepção conforme as transformações do meio ambiente que perpassa.

Já Mc Mahon (2009, p. 55, grifo nosso) descreve que Sócrates acreditava que felicidade era o bem supremo, senão vejamos:

O desejo humano é ubíquo, transbordando de todos os lados e entrando em todas as coisas. Ao conferir-lhe um objectivo novo e compreensivo e afirmar que ele está ao nosso alcance, Socrátes e Platão criam uma ânsia de tremendo poder. A sua felicidade é a soma de todos os desejos, o último lugar de repouso de Eros, o bem supremo. Como tal, diz Sócrates, a felicidade é uma <força poderosa e imprevisível $>$. Provavelmente, até ele ficaria surpreendido com as estranhas direcções a que a felicidade conduziu a posteridade - tão longe que quase podemos imaginar, como ele, que o nosso desejo natural de felicidade é completamente natural, nada devendo a estas antigas fantasias.

E continua McMahon (2009, p. 62) complementando o entendimento de "felicidade" por Aristóteles:

Aristóteles prescreve um regime permanente de habituação à virtude, o elemento mais estável e controlador na gestão da felicidade. Ele percebe que o estudo da virtude nunca poderá ser uma ciência exacta, com regras de comportamento infalíveis decretadas a partir de cima. Sugere, como alternativa, que a virtude seja desenvolvida através da prática, para que se torne gradualmente instintiva, com os indivíduos desenvolvendo um sentido inerente da reação certa com que enfrentar as muitas arbitrariedades da vida. A regra principal é a famosa doutrina do meio-termo de Aristóteles, que nos aconselha a regular o nosso comportamento entre os extremos. Através da razão, da prática e do exemplo, o homem virtuoso passará a conhecer o meio-termo apropriado entre a cobardia e a intrepidez, ou a avareza e a prodigalidade, ou a jactância e a auto-reprovação. Desenvolverá as adequadas virtudes de carácter - coragem, liberalidade e dignidade - e pautará o seu 
comportamento pelas mesmas. Examinando pormenorizadamente algumas dessas virtudes - magnanimidade, moderação, delicadeza, modéstia, benevolência e justa indignação, entre outras - Aristóteles propõe um ideal de harmonia e equilíbrio em que o desejo é moderado pela razão, e a vida levada de harmonia com essa nossa faculdade humana superior.

As definições de Sócrates, Platão e Aristóteles nos direciona para outras definições de felicidade. Aquela definição do bem supremo da vida, comparando com atitudes de deuses, a virtude plena, com a adoção da razão acima de tudo, visto que apenas os que se dedicam ao estudo podem assimilar.

Nesse sentido Gabardo (2017, p. 108, grifo nosso) esclarece que:

\begin{abstract}
A felicidade, mais do que um grau de satisfação verificável empiricamente, deve ser um fim estabelecido por princípio e não por critérios pragmáticos. Outra razão, portanto, que justifica a incompatibilidade entre a ideia de subsidiariedade (ou desenvolvimento como liberdade) e a proposta de desenvolvimento como felicidade. O critério de subsidiariedade depende da verificação de eficiência empírica do sistema. Sendo assim, decorre, em maior ou menor grau, de uma percepção pragmática da realidade e não de um paradigma principiológico (como propõe, corretamente, o sistema constitucional brasileiro).
\end{abstract}

Por outro lado, essa virtude humana, principalmente no que se refere à dignidade, no melhor da razão do homem que não pode deixa de a exercer, nos remete ao bem supremo, a vida, e consequentemente, o bem comum.

Relacionando, então, o pensamento de felicidade como ato de liberdade, como foi buscado nas principais revoluções (como a Independência dos Estados Unidos e a Revolução Francesa), Arendt (2011, p. 168, grifo nosso) nos traz os seguintes entendimentos:

[...] Por isso os homens de letras se voltaram para o estudo de autores gregos e romanos, não - e isso é decisivo - por causa de alguma sabedoria eterna ou beleza imortal que os livros pudessem conter, mas quase exclusivamente para se instruir sobre as instituições políticas ali descritas. $O$ que os levou de volta à Antiguidade não foi a busca da verdade, e sim a procura da liberdade política, e suas leituras serviam para lhes fornecer os elementos concretos para pensar e sonhar com tal liberdade. Nas palavras de Tocquerville, "chaque passion publique se déguisa ainsi em philosophie" [assim todas as paixões públicas se disfarçaram de filosofia]. Se tivessem a experiência concreta do que significava a liberdade para o cidadão individual, poderiam concordar com seus colegas americanos e falar da "felicidade pública"; pois basta lembrar a definição americana muito corrente da felicidade pública - dada, por exemplo, por Joseph Warren em 1772 - como fruto "do apego virtuoso e inabalável a uma Constituição livre" para entender a íntima semelhança que deve ter existido entre os conteúdos efetivos das fórmulas aparentemente distintas. A liberdade pública ou política e a felicidade pública ou política foram os princípios inspiradores que prepararam o espírito daqueles que, então, fizeram o que jamais tinham esperado fazer, e na maioria das vezes foram levados a ações pelas quais não sentiam nenhuma inclinação prévia. 
Consubstanciado nessa ligação entre liberdade e felicidade, Arendt trouxe o pensamento do bem comum, visto que a felicidade é o bem supremo: a vida. Caracterizando, assim, o objetivo principal do princípio da felicidade, o bem-estar de todos, procurando estabelecer esse mínimo existencial tão procurado por todos.

O princípio da felicidade é uma ramificação do princípio da dignidade da pessoa humana que tem como escopo principal a dignidade do homem, o bem-estar social, a valorização da vida, em transformação permanente para acompanhar o desenvolvimento das sociedades, como acrescentam Sarlet e Fensterseifer (2013, p. 49 e 50, grifo nosso):

\begin{abstract}
A dignidade (da pessoa) humana constitui conceito submetido a permanente processo de reconstrução, cuidando-se de uma noção histórico-cultural em permanente transformação quanto ao seu sentido e alcance, o que implica sua permanente abertura aos desafios postos pela vida social, econômica, política e cultural, ainda mais em virtude do impacto da sociedade tecnológica e da informação. Atualmente, pelas razões já referidas, pode-se dizer que os valores ecológicos tomaram assento definitivo no conteúdo do princípio da dignidade da pessoa humana. Portanto, no contexto constitucional contemporâneo, consolida-se a formatação de uma dimensão ecológica - inclusiva - da dignidade humana, que abrange a idéia em torno de um bem-estar ambiental (assim como de um bem-estar social) indispensável a uma vida digna, saudável e segura. Dessa compreensão, pode-se conceber a indispensabilidade de um patamar mínimo de qualidade ambiental para a concretização da vida humana em níveis dignos. Aquém de tal padrão ecológico, a vida e a dignidade humana estariam sendo violadas no seu núcleo essencial. A qualidade (e segurança) ambiental, com base em tais considerações, passaria a figurar como elemento integrante do conteúdo normativo do princípio da dignidade da pessoa humana, sendo, portanto, fundamental ao desenvolvimento de todo o potencial humano num quadrante de completo bem-estar existencial.
\end{abstract}

Da mesma forma, Gabardo (2017, p. 132, grifo nosso) acrescenta:

A dignidade, ao mesmo tempo em que é um princípio, também retrata um "direito à vida digna". Do mesmo modo, a felicidade, ao tempo em que é um princípio, comporta um "direito à vida feliz". O que não conduz imediatamente ao reconhecimento de um direito particular subjetivo passível de ser demandado pelo indivíduo junto ao Estado. Sua natureza é um "direito subjetivo"prima facie que consiste em um "direito originário à prestação" do qual decorrrem direitos derivados para os particulares (em geral, somente estes últimos demandáveis). Isso significa que a identificação de um aspecto subjetivo independe de possibilidade de judicialização e exequibilidade direta ou específica (este parece ser o caso dos direitos à segurança pública, ao pleno emprego ou mesmo ao meio ambiente), conforme a lavra de J.J. Gomes Canotilho. E nestes termos, também, possuem uma importante função na interpretação do sistema jurídico (CANOTILHO, 2000, p.465468).

Verifica-se, então, que o princípio da felicidade cuida exatamente do bem-comum, sem distinção, com garantias que o bem-estar será implementado através de políticas públicas dos Estados empenhados em aplicar esse bem-estar com o mínimo existencial. 
Gabardo (2017, p. 128, grifo nosso) também demonstra essa felicidade considerada, muitas vezes, como irreal, vejamos:

\begin{abstract}
Um princípio de caráter moral como aquele que impõe finalidade do Estado a felicidade da sociedade é um imperativo que ordena condicionalmente o agir (e por se referir ao agir, é essencialmente uma prática); porém, como estipula um dever, sendo irrelevante a capacidade humana de realizá-lo ou não, é, nesse sentido, teórico. De fato, a sua aceitação como realidade pode até ser enquadrada como uma utopia e, nesse sentido, é contrafactual. Isso não significa que o princípio da felicidade é irreal ou mesmo que não possa ser efetivamente aplicado (e aplicado em uma ordem jurídica). Consiste, portanto, em uma proposta de natureza normativa. Trata-se este de um modelo regulador da vida insubstituível quando se tem em vista uma sociedade como a brasileira, ainda carente de um Estado que se realize como social. A inexistência generalizada da felicidade mínima absolutamente é justamente um requisito fático para a ampliação da exigibilidade de uma condição normativa mais intensa. Condição esta cuja capacidade de interferência fática será sempre mais limitada do que seu escopo vem a determinar.
\end{abstract}

Ademais, todos têm o direito de serem livres para decidir o rumo do que for melhor para si, na sua felicidade individual, mas ao mesmo tempo, argumentar a felicidade pública ou política com a finalidade do bem comum, o que era exclusivo para aqueles que possuíam o ócio ou o direito de pensar.

Assim sendo, pelas análises doutrinarias realizadas, percebemos que a "felicidade" é um estado de espírito que o homem deve perseguir, conquistar e manter para que ele tenha a sua dignidade humana preservada em todos os momentos e em todos os espaços onde estiver: no trabalho, no seu templo religioso, nas suas relações sociais, no espaço urbana que desfruta concomitantemente com outros seres (animais, vegetais, homens, etc..).

Para manter esse equilíbrio, da mesma forma que o homem do pretérito (o conquistado, o escravo, o de raça inferior) lutou para conseguir estabelecer como norma jurídica, princípios fundamentais (tais como o da liberdade, da igualdade, etc...), o homem contemporâneo luta agora, para informar sobre a necessidade de normatizar o "Principio da Felicidade" para que ele possa trazer garantias ao ser humano.

E é nesse sentido que faremos agora a análise do princípio da felicidade, no contexto do meio ambiente urbano.

\title{
3 MEIO AMBIENTE URBANO
}

Quando se fala de "Meio Ambiente" a primeira ideia que se vem à cabeça, é a de que estar-se-ia falando da fauna e a flora; entretanto, a expressão "meio ambiente" traz consigo diversas interpretações, diversos espaços físicos e psicológicos; tais como "meio ambiente 
psicológico, meio ambiente do trabalho, meio ambiente rural, meio ambiente urbano, etc..." cada um desses espaços, seja ele material ou imaterial, possui características e contornos próprios. Ou seja, há diversos ambientes, visto que, a cada momento, se forma novos "meios ambientes" com novas características e qualidades.

Nesse sentido, vejamos a explicação de Silva (2013, p. 19 e 20, grifo nosso):

A palavra "ambiente" indica a esfera, o círculo, o âmbito que nos cerca, em que vivemos. Em certo sentido, portanto, nela já se contém o sentido da palavra "meio". Por isso, até se pode reconhecer que na expressão "meio ambiente" se denota certa redundância, advertida por Ramón Martín Mateo, ao observar que "se utiliza decididamente a rubrica Derecho Ambiental em vez de Derecho Del Medio Ambiente, abandonando uma prática lingüística pouco ortodoxa que utiliza cumulativamente expressões sinônimas ou, ao menos, redundantes, no que incide o próprio legislador. Em Português também ocorre o mesmo fenômeno, mas essa necessidade de reforçar o sentido significante de determinados termos, em expressões compostas, é uma prática que deriva do fato de o termo reforçado ter sofrido enfraquecimento no sentido a destacar, ou, então, porque sua expressividade é mais ampla ou mais difusa, de sorte a não satisfazer mais, psicologicamente, a idéia que a linguagem quer expressar. Esse fenômeno influencia o legislador, que sente a imperiosa necessidade de dar aos textos legislativos a maior precisão significativa possível; daí por que a legislação brasileira, incluindo normas constitucionais, também vem empregando a expressão "meio ambiente", em vez de "ambiente", apenas.

E continua Silva (2013, p. 20, grifo nosso) esclarecendo sobre a existência de diversos tipos de meio ambiente que se integram:

O ambiente integra-se, realmente, de um conjunto de elementos naturais e culturais, cuja interação constitui e condiciona o meio em que se vive. Daí por que a expressão "meio ambiente" se manifesta mais rica de sentido (como conexão de valores) do que a simples palavra "ambiente". Esta exprime o conjunto de elementos; aquela expressa o resultado da interação desses elementos. $O$ conceito de meio ambiente há de ser, pois, globalizante, abrangente de toda a Natureza original e artificial, bem como os bens culturais correlatos, compreendendo, portanto, o solo, a água, o ar, a flora, as belezas naturais, o patrimônio histórico, artístico, turístico, paisagístico e arqueológico.

Todavia, o meio ambiente necessita abranger todas as áreas possíveis, como explicam Pozzetti e Tavares (2019, p. 250, grifo nosso):

Pelo exposto, o conceito de meio ambiente engloba, além dos recursos ambientais, como solo, água, flora, as diversas criações do homem, que se consubstanciam em inúmeros aspectos, das mais diversas naturezas, como: imóveis históricos; obras de arte; lendas urbanas; línguas; enfim, tudo o que possa vir a contribuir para o bem-estar e a dignidade da pessoa humana.

É importante salientar o elo que existe entre o meio ambiente com o "bem-estar" para que se torne "equilibrado"; a simples elucidação do que é meio ambiente, não satisfaz o seu objetivo; deve-se aplicar boas práticas, como as políticas públicas, pelo Estado, e ações 
sociais, pela sociedade civil, bem como a de informar a população sobre exigir a garantias dos seus direitos fundamentais.

Nessa linha de raciocínio, se tornou necessário essa nova perspectiva quanto à nomenclatura do meio ambiente, consagrando novos termos específicos para que o ser humano possa conviver harmoniosamente com a natureza que o rodeia, sem que prejudique as vidas humanas e não humanas, como esclarecem Sarlet e Fensterseifer (2013, p. 99, grifo nosso):

A ampliação da noção de dignidade da pessoa (a partir do reconhecimento da sua
necessária dimensão ecológica) e o reconhecimento de uma dignidade da vida não
humana apontam para um releitura do clássico contrato social em direção a uma
espécie de contrato ecológico, com o objetivo de contemplar um espaço para tais
entes naturais - pelo menos na perspectiva de uma tutela jurídico-objetiva dos seus
interesses - no âmbito da comunidade estatal. Nesse sentido, Serres aponta para a
necessidade de se apostar, no contexto político-jurídico contemporâneo, na
concepção de um contrato natural, onde o ser humano abandone a sua condição
de dominador e "parasita" em face do mundo natural e assuma em face deste
uma postura caracterizada pela reciprocidade na relação entre ser humano e
ambiente, ou seja, aquilo que a Natureza dá ao homem é o que este deve dar a
ela, tornando-a, de certo modo, sujeito de direito. Assim, da mesma forma
como a Declaração dos Direitos do Homem buscou por fim ao parasitismo entre
seres humanos, é chegado o momento histórico de, por meio de um contrato
natural, se acabar, ou, pelo menos, minimizar, o impacto maléfico do
parasitismo do Homem em relação à Natureza. A partir de tal compreensão,
deve-se caminhar no sentido de ampliar o espectro de reconhecimento de sujeitos de
direito no sentido de, contemplando um contrato natural ou ecológico de
reciprocidade e interação entre os pactuantes.

Dessa forma, é importante que seja observado o meio ambiente em que se vive e, mesmo que este já tenha sido degradado, não se deve contribuir para a manutenção ou continuar poluindo esse meio; e esta regra vale, especialmente para o meio ambiente urbano.

No tocante a construção de meio ambiente urbano, no Brasil, Pozzetti e Cromwell (2016, p. 144) observam que "A acelerada urbanização ocorrida em larga escala a partir do século XX, pela qual passou a sociedade brasileira, repercutiu numa das principais dificuldades sociais experimentadas no mundo moderno, qual seja, o planejamento urbano das cidades".

Portanto, o meio ambiente urbano deve ser trabalhado e cuidado para a melhoria da qualidade de vida, de forma una, para todos, como assinala Silva (2013, p. 22 e 23, grifo nosso):

Não constituem aqueles aspectos meios ambientes estanques, como já tinha observado de outra feita, pois se acham integrados numa visão unitária a serviço da qualidade de vida humana, convergindo para a formação do meio ambiente urbano. Tanto é assim que o "interesse pela qualidade do meio ambiente urbano constitui, em grande parte, a convergência de outros dois temas públicos que se acham em 
plena evolução", conforme nota Harvey S. Perloff. "Um deles é o interesse pela qualidade do meio ambiente natural: qualidade do ar, da água, áreas florestais e de outros recursos. O outro é o interesse pelo desenvolvimento de nossas comunidades urbanas: com todos os temas que entram na rubrica de uma planificação mgais tradicional da cidade, mas centrada mais recentemente num interesse especial pelos seres humanos da cidade. A qualidade da vida de todas as pessoas que se reúnem nas comunidades urbanas está claramente influenciada por quanto suceda nos meios, natural e obra do Homem, que se acham diretamente inter-relacionados.

Assim sendo, impõe-se a reflexão da importância do meio ambiente urbano para convivência entre todos, visto que as cidades não devem simplesmente construir um bairro, por exemplo, de forma aleatória, sem observar os limites entre cada ocupação, independentemente que seja um imóvel para residência ou uma rua para melhorar as condições de trânsito. E é nesse sentido que Pozzetti e Crommewel (2016, p. 146) destacam:

Dessa forma, a proteção ao meio ambiente deve ser vista a partir do olhar da teoria dos direitos fundamentais, uma vez que a pessoa humana é destinatária do direito ambiental. Essa constatação é observada em razão do viés antropocêntrico dado pelo constituindo, ao estabelecer como fundamento da República a dignidade humana (Inciso III, do art. $1^{\circ}$, da $\mathrm{CF} / 88$ ).

A harmonia entre as necessidades de cada população contribui para que haja desenvolvimento naquele local e não apenas um "lugar para morar" sem que haja qualidade de vida e condições para o bem comum de todos, abrangendo a sustentabilidade e, concomitantemente, observando-se os aspectos: econômico, social, político e cultural, como bem observam Pozzetti e Tavares (2019, p. 251, grifo nosso):

Assim sendo, temos que o meio ambiente urbano sustentável apenas se concretiza quando se equilibra o desenvolvimento econômico com a preservação do meio ambiente urbano, inclusive em aspectos culturais.

Dessa forma, caracteriza-se como de suma importância viver em um meio ambiente urbano adequado, com qualidade de vida, com dignidade; pois o ser humano deve se sentir parte do meio ambiente em que vive, caso contrário, não se sentirá incluso naquele espaço, o que certamente lhe trará desconforto e inquietação. Assim, o meio ambiente urbano, em que esse ser humano vive, deve lhe proporcionar: qualidade de vida, cidadania, saúde, educação, moradia digna, entre outros.

\section{APLICAÇÃO DO PRINCÍPIO DA FELICIDADE NO MEIO AMBIENTE URBANO}

O princípio da felicidade com o intuito de preservar e aplicar o bem comum, tanto na felicidade individual como na felicidade pública, procura equilibrar o meio ambiente, 
principalmente, no que se refere ao meio ambiente urbano, visto que ainda sofre restrições, pois exige condições que geram gastos e obstáculos a serem eliminados.

Para o gestor público, o caminho mais fácil e rápido, muitas vezes, cria condições políticas para que o tenha seu enaltecimento, deixando de lado as políticas que devem ser seguidas para meio ambiente urbano equilibrado, como exemplo, a moradia digna, uma luta histórica da população brasileira, ora apresentada por Pozzetti e Loureiro (2020, p. 288, grifo nosso):

\begin{abstract}
A exploração econômica marcou a ocupação do solo brasileiro. Historicamente, fruto de colonização e de exploração, o território brasileiro foi utilizado para a retirada de recursos naturais e minerais que geravam lucro para seu colonizador. Por este motivo, é fácil afirmar que o acesso formal à terra sempre foi garantido aos que detinham condições financeiras. Por esta razão, aqueles que não possuíam capital eram marginalizados, exercendo a ocupação irregular de solos que não apresentavam interesse financeiro para o Poder Público.

Com o processo de industrialização nacional e o êxodo rural resultante, as populações passaram a ocupar os centros urbanos, habitando, de maneira desordenada, os locais onde se estabeleciam. Por esta razão, durante muito tempo, as populações eram removidas dessas ocupações irregulares e iam estabelecendo-se em lugares diversos.
\end{abstract}

E, nessa linha de raciocínio, Pozzetti e Loureiro (2020, p. 284, grifo nosso) destacam a importância de que o meio ambiente urbano possa trazer dignidade ao ser humano para, assim, lhe trazer felicidade:

A regularização fundiária urbana guarda íntima relação com os dilemas do Poder Públicono cumprimento de deveres constitucionais por vezes conflitantes.Se ao Estado cabe, por um lado, fazer respeitar o princípio do ordenamento territorial e do meio ambiente sadio e equilibrado, por outro lado, cabe-lhe garantiraoscidadãoso direito à moradiadigna eao desenvolvimento econômico sustentável.

Corroborando essa luta, inclusive, na história do mundo, Lopes (2019, p. 50, grifo nosso) argumenta o poder da terra na vida dos povos, na era feudal, vejamos:

A propriedade da terra é uma das coisas mais distintas do sistema medieval. Compreendia na verdade dois poderes para nós muito distintos: o direito de jurisdição (julgar as disputas dentro do território respectivo) e o que chamaríamos hoje um direito de propriedade (na verdade algumas parcelas de poder de exploração da terra). A terra era uma entidade sobre a qual havia servidões entre prédios e terras, havia serviços ligados à terra e ao direito sobre a terra. Paolo Grossi afirma que para os medievais a terra era o centro do pensamento, e o direito subordinava-se a uma dinâmica que se encontrava na apropriação deste bem. (gn)

Havia ligações perpétuas de fidelidade entre vassalos e senhores, como visto, e ligações pro-vita entre peão e senhor (o peão não perdia a terra, pois seu direito a permanecer nela era também vitalício). Os direitos eram limitados quanto a seu exercício (não se podia tudo) e quanto ao tempo (a hereditariedade não era total). Quais eram os direitos sobre a terra? Uma tenência geral (em inglês 
manor): correspondia ao feudo propriamente dito, que dava ao senhor (dominus) o direito de caça, o direito de pesca e as banalidades, isto é, obrigações impostas aos peões de (a) cozer o pão no forno senhorial, (b) moer o trigo no moinho do senhor, (c) pagar prestações sobre tais "serviços públicos" mantidos pelo senhor. Estas banalidades eram como que privilégios (monopólios) do senhor direto da terra. Com o tempo, tais direitos vão se monetarizando e transformando-se em pagamento de taxas e tributos. O desapossamento sem justificativa era uma violência pessoal e grave, era uma diffidatio, que, como visto, implicava o rompimento do dever de lealdade.A posse era um direito que se transmitia, se conservava e não permitia a alienabilidade. Daí a famosa adscrição do servo à gleba. Quando se começa a aceitar a alienabilidade da posse começa a acabar o feudalismo e a servidão.

A luta pela posse de terras, ocorre até os dias atuais, vislumbra-se também uma "escravidão" ou "servidão", pois permanece essa subordinação para utilizar a posse da terra, diante da falta de políticas públicas com solução digna, semelhante como foi acima citado.

Cumpre ressaltar que as políticas públicas habitacionais, ainda é o grande enfoque no meio ambiente urbano, visto que facilitam a compra da casa própria, com financiamentos atrativos por bancos e financeiras e, ainda, o apoio do Governo Federal, com o objetivo de eliminar o déficit habitacional e o pagamento de aluguel, muitas vezes a qualquer preço, como avalia Ramalhoso (2016, p.e., grifo nosso):

Muitas vezes, são as próprias construtoras que decidem a localização do empreendimento. Orientadas pela lógica financeira, elas constroem em terras baratas situadas em locais periféricos e até em antigas áreas rurais, acessíveis por via única - às vezes, inclusive, somente por rodovia --, criando "frentes pioneiras" de urbanização. Em muitos desses casos, as moradias ficam distantes de equipamentos que oferecem serviços essenciais como educação e saúde, de sistemas de transporte e de locais de empregos.

Ou seja, a produção habitacional nem sempre é feita de forma integrada à cidade. Isso resulta em uma séria de dificuldades para os moradores, que passam a ter de gastar mais tempo e dinheiro nos deslocamentos, que passam a ter de gastar mais tempo e dinheiro nos deslocamentos, e para o poder público, que precisa estender a estrutura de seus serviços. Nos casos em que as prefeituras participam da escolha do terreno, os problemas citados acima tendem a ser minimizados.

Por outro lado, a legislação brasileira contribui para que haja melhores condições no que tange ao meio ambiente urbano, e principalmente, ao exemplo indicado da moradia digna, ao interagir com a função social da propriedade, tanto rural como urbana, como elencam Pozzetti e Loureiro (2018, p. 291, grifo nosso):

Constitucionalmente previsto no art. $5^{\mathbf{0}}$, inciso XII, o direito à propriedade participa do rol de direitos fundamentais, desde que atenda à sua função social. Além de constituir princípio fundamental, a função social da propriedade está positivada no rol de princípios do art. 170 da Constituição, que norteia a ordem econômica, e na previsão do art. 184, sobre a política agrícola e fundiária, que tutela o imóvel rural e sua função social. Entretanto, interessa aqui a função social da propriedade. 
A Constituição prevê, em seu art. $182, \mathbf{~}^{\circ}$, que a propriedade urbana que atenda às exigências fundamentais de ordenação das cidades previstas no plano diretor cumprirá a sua função social.

Dessa maneira, nota-se a delicadeza entre o princípio da felicidade como instrumento para garantir o atendimento da sua função social do meio ambiente urbano, cumprindo as exigências fundamentais para a dignidade da pessoa humana, ou seja, o equilíbrio, com a elevação da qualidade de vida e a efetivação dos direitos fundamentais.

Da mesma forma, que a sociedade clama pela efetivação dos direitos humanos e a sua constitucionalização como direitos fundamentais, a efetivação das políticas públicas contribuem para que projetos elaborados, com base no equilíbrio e na sustentabilidade, desenvolvam o meio ambiente urbano e aplicam o princípio da felicidade.

A cidade inteligente é um exemplo da aplicação do princípio da felicidade no meio ambiente urbano, que tem origem no Vale do Silício, na Califórnia, Estados Unidos da América - EUA,primeiramente com o termo Smart Community, como destacam Coutinho e tal (2019, grifo nosso):

As primeiras referências a Cidades Inteligentes vieram do Vale do Silício, na Califórnia (USA), através do termo Smart Community, por volta de 1993. Essa terminologia remetia a uma "associação direta com a otimização, desenvolvimento sustentável e positivo de uma cidade ou região" (Lindskog, 2004, p.2). Ainda na década de 1990, utilizou-se o conceito de Cidades Digitais, quando se acreditava que o simples fato de inserir uma camada de tecnologia sobre as cidades resolveria grande parte dos problemas. Hoje predomina o termo Cidades Inteligentes que emergiu com o protocolo de Quioto em que é "uma comunidade que faz um esforço consciente para usar a tecnologia da informação para transformar a vida e o trabalho dentro de seu território de forma significativa e fundamental, em vez de seguir uma forma incremental" (Komninos, 2006, p. 13). A União Internacional de Telecomunicações define cidade inteligente como uma cidade que aproveita a infraestrutura de TIC para melhorar a qualidade de vida e o bem-estar dos cidadãos, garantindo o crescimento econômico sustentável, otimizando os serviços municipais, reforçando a prevenção de desastres e fornecendo mecanismos eficazes de governança. Nam e Pardo (2011) enfatizam que as soluções verdadeiramente inteligentes são aquelas que colocam as pessoas no centro das cidades inteligentes ao invés de a tecnologia.

Para tanto, cumpre elucidar o conceito de smart city, na tradução livre cidade inteligente, conforme definem Rizzon e tal (2017, p. 128, grifo nosso):

Para Capdevila and Zarlenga (2015) o conceito smart city sugere que uma cidade é inteligente quando reforça a inventividade e a criatividade de seus cidadãos. Já Hollands (2008) identifica cinco características principais de uma cidade inteligente: incorporação generalizada das TIC no tecido urbano; desenvolvimento urbano orientado para negócios e uma abordagem neoliberal de governança; foco na dimensão social e humana da cidade a partir de uma perspectiva de cidade criativa; adoção de uma agenda de desenvolvimento de 
comunidades inteligentes com programas visando à aprendizagem social, educação e capital social e; foco na sustentabilidade social e ambiental.

\title{
[...] omissis
}

Cidadãos são os principais atores ou agentes no desenvolvimento de Smart Cities e, portanto, em grande parte moldam padrões da cidade, incluindo padrões sociais, econômicos, ambientais e de governança. Desenvolver redes de cidadãos é uma função crítica para uma cidade frente aos seus esforços de planejamento. Desenvolver capacidades para soluções em rede irá criar fortes comunidades de cidadãos que têm a capacidade de intervir e resolver problemas locais, em coordenação com instituições locais e estruturas de governança (Desouza \& Flanery, 2013).

Esse é o grande mérito: colocar a população no centro das atenções, objetivando o bem comum, aplicando o princípio da felicidade, e especificamente, neste caso, no meio ambiente urbano, como exemplo, smart city, em tradução livre, cidade inteligente, no Estado do Pará, no Brasil.

Canaã dos Carajás, conforme esclarece o Site Belem.com.br (2020, p.e., grifo nosso), foi a primeira cidade inteligente do Brasil, localizada no Estado do Pará:

A cidade de Canaã dos Carajás, no sudeste do Pará, deve ser a primeira cidade do País a se tornar inteligente, seguindo o conceito de Smart Cities, que está sendo desenvolvido por diversas universidades brasileiras, entre as quais a Universidade Federal do Pará (UFPA) e a Universidade de São Paulo (USP), instituição líder do projeto IARA (Inteligência Artificial Recriando Ambientes). Canaã é um dos municípios parceiros desse projeto, uma inovação no País.

O projeto prevê a utilização de tecnologias como Inteligência Artificial e Internet das Coisas para gerar eficiência nas operações urbanas das cidades, além do estímulo à implantação de startups e spin offs (empresas jovens de tecnologia, sediadas em Canaã dos Carajás) e à formação de mão de obra qualificada para atuação em diversas áreas tecnológicas.

Carneiro (2020, p.e., grifo nosso) complementa as metas para implementação do projeto da cidade de Canaã dos Carajás como cidade inteligente, vejamos:

\begin{abstract}
O projeto Smart Cities é uma das ações do Pacto do Canaã, que visa tornar o município um dos melhore para se viver no Brasil até 2035. A proposta tem duas vertentes: a primeira é a implementação de várias funcionalidades de melhoria em áreas como saúde, segurança, educação, trânsito, meio ambiente, acessibilidade, indústria 4.0 e outras. A segunda está no fomento de "startups", empresas de tecnologias instaladas em Canaã dos Carajás para o desenvolvimento de todas essas funcionalidades, através de custeio de projetos pelo Fundo Municipal de Desenvolvimento Sustentável (FMDS).
\end{abstract}

Dessa forma, confirma-se a relevância do meio ambiente urbano e a necessidade da aplicação do princípio da felicidade para garantir o bem comum, o bem-estar de todas e todos, com ênfase na qualidade de vida e, consequentemente, melhores condições dignas de saúde, 
educação, de desenvolvimento econômico, entre outros; mas principalmente com o objetivo de fomentar o desenvolvimento sustentável, base para felicidade de todos os seres humanos.

\section{CONCLUSÃO}

A problemática que movimentou essa pesquisa foi a de se verificar qual a contribuição do Princípio da Felicidade na formação das cidades inteligentes. Os objetivos da pesquisa foram concretizados, à medida em que se analisou a forças normativas dos princípios, no âmbito jurídico, bem como se definiu de forma eficaz "meio ambiente urbano" e "felicidade".

Da análise, verificou-se que o princípio da felicidade como garantidor de políticas públicas para alcançar o bem-estar, seja de forma individual ou coletiva (pública), deve ser incorporado no rol dos princípios de direito, vez que tem intima ligação com os direitos fundamentais do ser humano.

As cidades inteligentes que estão sendoconstruídas, em alguns municípios, no Brasil(como o município de Canaã dos Carajás, localizado no Pará, em plena região amazônica), traduzem a expectativa do princípio da felicidade e sua aplicação no meio ambiente urbano, refletindo a junção dessas duas políticas públicas, que ainda estão sendo subutilizadas.

Colocar o ser humano como ator principal para alcançar o bem comum, com qualidade vida, visando o bem-estar individual e coletivo, refletindo, assim, nas atividades econômicas, financeiras, educacionais, alcançando a saúde e outros. Ao mesmo tempo, incluindo a população nas diretrizes de gestão para suas necessidades com transparência, excluindo a possibilidade de corrupção, trazendo felicidade para todas as vidas humanas e não humanas.

Assim, chegou-se à conclusão de que a elaboração de formas garantidoras para a união da sociedade, das instituições públicas e privadas para garantir políticas públicas e legislações para melhoria da qualidade de vida, são reflexos do princípio da felicidade, e no caso, específico no meio ambiente urbano, confirmando a importância de ambos.

Dessa forma, a felicidade não deve ser considerada como algo irreal ou subjetivo, a felicidade deve ser instituída e garantida pelo Estado, o princípio da felicidade é um instrumento para aplicação do bem comum e, conjuntamente com o meio ambiente urbano 
equilibrando, buscam equilíbrio e garantem qualidade de vida para vidas humanas e não humanas.

\section{REFERÊNCIAS}

ARENDT, Hannah. Sobre a Revolução. Tradução: Denise Bottman. São Paulo: Companhia das Letras, 2011.

ÁVILA, Humberto. TEORIA DOS PRINCÍPIOS da definição à aplicação dos princípios jurídicos. São Paulo: Malheiros, 2021.

BELEM.COM.BR. Canaã dos Carajás: primeira cidade inteligente do Brasil. Disponível em: https://belem.com.br, consultado em 02 abr.2021.

CARNEIRO, Kleyskennyson. Desenvolvimento Econômico: prefeito e equipe de governo visitam Universidade de São Paulo. Prefeitura Canaã dos Carajás, 2020. Disponível em: www.canaadoscarajas.pa.gov, consultado em 02 abr.2021.

BRASIL. Decreto-Lei n. 4.657, de 04 de setembro de 1942. Lei de Introdução às Normas do Direito Brasileiro. Redação dada pela Lei n. 12.376, de 2010. Congresso Nacional, Brasília, 2010.

BRASIL. Constituição da República Federativa do.Congresso nacional, Brasília, 1988.

COUTINHO, Mauro Margalho et al. Coprodução Sociedade Civil - Governo na Constituição de Cidades Inteligentes no Estado do Pará. Revista de Administração Contemporânea. vol.23, n. 5. Curitiba. Set-Out.2019. Disponível em: https://doi.org/10.1590/1982-7849rac2019190036, consultado em 02 abr.2021.

FERREIRA, Marie Joan Nascimento. A felicidade como condição humana da vita activa, sob a ótica de Hannah Arendt. [Recurso eletrônico on-line] organização CONPEDI; Coordenadores: Daniele Marques de Moraes e Jaime Ruben Sapolinski Labonarski. Montevidéu: CONPEDI, 2016.2 Disponível em: http://conpedi.danilolr.info/publicacoes/9105o6b2/v2zhni84/JgkvvCI4SfW3p060.pdf, consultado em 02 abr.2021

GABARDO, Emerson. A felicidade como fundamento teórico do desenvolvimento em um Estado Social. Revista Digital de Direito Administrativo. vol.5, n. 1. São Paulo, 2018. Disponível em: https://www.revistas.usp.br/rdda/article/view/136849/137642, consultado em 02 abr.2021.

LOPES, José Reinaldo de Lima. O direito na história. Lições introdutórias. São Paulo: Atlas, 2019.

McMAHON, Darrin. Uma história da Felicidade. Tradução: Jaime Araújo. Revisão: Luís Milheiro. Lisboa: Edições 70, 2009. 
POZZETTI, Valmir César; CROMMWEL, Adriana Carla. O direito do hipossuficiente à assistência gratuita, em projetos de construção urbanística, como instrumento da política urbana. Revista de Direito Urbanístico, Cidade e Alteridade. e-ISSN: 2525-989X| Curitiba | v. 2| n. 2| p. 143-163| Jul/Dez. 2016. Disponível em: file://C:/Users/Valmir/AppData/Local/Temp/1324-3096-1-SM.pdf, consultado em 14 abr. 2021.

POZZETTI, Valmir César; TAVARES, Jaíse Marien Fraxe. Grafitagem no meio ambiente urbano: arte ou poluição visual? Revista Direito Ambiental e Sociedade. v. 9, n.2, p. 241 270, maio-ago.2019. Disponível em: file:///C:/Users/home/AppData/Local/Temp/788829529-1-PB.pdf, consultado em 02 abr.2021

POZZETTI, Valmir César; LOUREIRO, Rebecca Lucas Camilo Suano. Impactos da legitimação fundiária no meio ambiente urbano. Revista Jurídica Unicuritiba. Curitiba. v. 02, n.59, p. 283-310, abril-junho.2020. Disponível em: file://C:/Users/Valmir/AppData/Local/Temp/4092-371376315-1-PB.pdf, consultado em 14 abr. 2021.

POZZETTI, Valmir César; POZZETTI, Laura; POZZETTI, Daniel Gabaldi. A importância do princípio da precaução no âmbito da conservação ambiental. Revista Campo Jurídica, barreiras -BA, v.8, n. 2, p. 175-189, Julho-Dezembro, 2020. Disponível em: http://www.fasb.edu.br/revista/index.php/campojuridico/article/view/661, consultado em 12 mar. 2021

RAMALHOSO, Wellington. Minha casa, minha vida deu certo? Veja pontos positivos e negativos. São Paulo: UOL notícias, 2016. Disponível em: https://noticias.uol.com.br/cotidiano/ultimas-noticias/2016/06/19/minha-casa-minha-vida-deucerto-veja-pontos-positivos-e-negativos.htm, consultado em 02 abr.2021.

RIZON, Fernanda et al. Smart City: um conceito em construção. Revista Metropolitana de Sustentabilidade. vol. 7, n. 3. São Paulo. Set-Dez.2017. Disponível em: https://revistaseletronicas.fmu.br/index.php/rms/article/view/1378, consultado em 02 abr.2021.

SARLET, Ingo Wolfgang. FERNSTERSEIFER, Tiago. Direito Constitucional Ambiental. Constituição, Direitos Fundamentais e Proteção do Ambiente. 3.ed.rev., atual.e.ampl. São Paulo: Editora Revista dos Tribunais, 2013.

SILVA, José Afonso da. Direito Ambiental Constitucional. 10.ed.atual. São Paulo: Editora Malheiros, 2013. 